\title{
THE DEFENSE OF PRICE DISCRIMINATION IN NETWORK AND INFORMATION GOODS MARKETS
}

\author{
Ivan Soukal'
}

1 University of Hradec Králové, Faculty of Informatics and Management, Department of Economics, Czech Republic, ORCID: 0000-0003-3468-0270, ivan.soukal@uhk.cz.

\begin{abstract}
It is not uncommon that articles focused on consumer-price interaction in the network and information goods market swiftly condemn price discrimination as an obfuscation, on-purpose price complexity, or market failure. The reason is a general neoclassical rule of an efficient market where prices are set at marginal cost with no price discrimination. However, the matter is more complicated. This review provides authors an overview of why, where, and which type of price discrimination should be viewed by different optics. Goods such as software, cell carrier services, electronic newspapers subscription, electric energy supply, payment accounts, books, copyrighted content streaming, etc, cannot be treated like manufactured goods. The reasons are specific conditions - substantial and/or repeated fixed/sunk cost, economies of scale, and demand heterogeneity. Recognized economist W. J. Baumol described marginal cost set prices under these conditions as an 'economic suicide'. Reviewed articles showed that firms are forced to adopt price discrimination in order to recover their costs and to serve more consumer segments. Reviewed authors provided facts to support the use of multipart tariffs, dynamic pricing, versioning, bundling, and Ramsey pricing. These conclusions are used for suggestions on how several studies of information and network goods should be modified. Modifications are related mostly to model assumptions and pricing conclusions. I argue that, in the case of information and network goods, there is justified price discrimination. Hence, there is a certain justified level of price complexity that has to be accepted and not taken as automated evidence of inefficiency, market power, and consumer exploitation.
\end{abstract}

Keywords: Price discrimination, marginal cost, price complexity, price obfuscation, network goods, information goods.

JEL Classification: L11, D24.

APA Style Citation: Soukal, I. (2021). The Defense of Price Discrimination in Network and Information Goods Markets. E\&M Economics and Management, 24(4), 39-55. https://doi. org/10.15240/tul/001/2021-4-003

\section{Introduction}

There can be found many articles in which price discrimination was swiftly considered as a negative phenomenon, mainly behavioural economy studies. Such studies described it as pricing leading to consumer-detrimental effects and increasing companies' profits. However, this rule is not as universal as it may seem. The case is more complicated because exceptions do exist, and they are far from rare - software, cell carrier services, real-time stock quotes, electronic newspapers subscription, electric energy supply, payment accounts, books, copyrighted content streaming, file storage, and more. These information and network goods were often treated as any mass-produced physical goods, which is not an adequate approach. The article's ambition is to contribute to a change. I hope that after reading the article, you would agree that price discrimination in the case of information and network goods should be viewed by different optics. 
Price discrimination was seen in many studies as being created on purpose to exploit the bounded rationality and biases of consumers. Such a situation was described by various price-related terms in studies of information and network goods: price complexity (Carlin, 2009; Friesen \& Earl, 2015; Homburg et al., 2014; Kalaycı, 2015), price intransparency (van Boom, 2011), tariff complexity (Lunn, 2013), obfuscation (Chioveanu \& Zhou, 2013; Ellison \& Wolitzky, 2012; Gu \& Wenzel, 2014, 2017; Spiegler, 2016), price partitioning (van Boom, 2011), cost complexity (Kalaycı \& SerraGarcia, 2016) and such. A commented overview can be found, e.g., in Grubb (2015). Sometimes the mere presence of dynamic or multi-part tariffs was explained as a sign/result of market power (Carlin, 2009; Grubb \& Osborne, 2015). These authors would welcome efficient market reached through marginal-cost pricing with no price discrimination. I ask the question, why recognised economist, Nobel prize candidate Baumol sharply disagreed? He described marginal cost pricing for such goods as 'a financial suicide' and 'a recipe for insolvency' (Baumol \& Swanson, 2003; Baumol, 2006). I argue that several specific conditions were ignored in mentioned behavioural economy studies: repeated and substantial fixed/ sunk costs versus near-zero marginal cost, economies of scale, demand heterogeneity.

This review aims to provide authors studying information and network goods a complex overview of why, where, and which type of price discrimination cannot be considered plainly as an obfuscation, on-purpose price complexity, market oddity, or failure. I gathered studies from the last fifteen years as evidence. Studies were analysed accordingly the PRISMA scheme 2009 (Liberati et al., 2009). Specific conditions forced firms to adopt price discrimination in order to serve the market at all or in a wider range of consumer segments. There are three stages to reach the goal. First, I introduced information and network goods-specific features and realworld examples. Second, I presented claims and conclusions from reviewed articles related to cost structure, economies of scale and demand heterogeneity. Third, I offered a pricing strategies overview to demonstrate the purpose of price discrimination. To sum up the introduction, this article is not yet another article that argues about the Cambridge paradigm of the efficient market or profit maximization. This article seeks to improve further behavioural or other studies focused on network and information goods.

The remainder of this article is organized as follows. Section 1 provides the theoretical background for surveyed pricing. Section 2 describes the search process according to PRISMA. Section 3 gives an overview of surveyed goods' features, summarises costpricing claims and conclusions. Section 4 confronts findings from reviewed articles with selected behavioural economy articles. The last section sums up the review in concluding remarks and comments on the review limits and further research.

\section{Price Discrimination}

The most relevant start for a price discrimination defense is Coase's (1946) marginal cost controversy problem. He contributed to a theoretical debate on whether decreasingaverage-cost industries should set prices at marginal cost. He reacted to Hotelling's (1938) support for marginal cost pricing and suggested that the welfare-optimal pricing is the multi-part tariff. They were discussing public utilities, i.e., typical network goods. Duffy (2004) concluded in his summarizing opinion on the marginal controversy matter that industry must be allowed to price above marginal cost to cover its fixed costs. This resonates in all reviewed articles, but the matter is wider and deeper. Therefore, we cannot settle with just Coase's (1946) conclusion because, among other problems, there was an assumption of cost attribution.

Maybe the most concise yet precise definition of price discrimination comes from Stigler (1987). He claims that price discrimination appears where at least two (or possibly more) similar goods are sold at different prices relative to their marginal cost of production. Price discrimination phenomena's most favourable conditions involve demand price for any unit which is independent of the price of sale of every other unit and, unit non-transferability from market to market but also consumer to consumer. Common pricing methods which I found, discussed or modelled in studied articles are described below:

1. No price discrimination: Linear, flat, uniform pricing: price per unit does not vary with quantity purchased (Vickers, 1997) and is applied to everyone regardless of time, 
quantity or segment. It is the simplest and straightforward pricing scheme from the point of view of both market sides. In economic theory by Robinson (1933), if set at marginal cost, this type of pricing is considered as the most market efficient since it creates no dead-weight loss.

2. First-degree price discrimination: Individual, personalized, customized pricing: a price is set individually for each consumer, and this price is led by a knowledge of the potential buyer's individual demand curve and be able to set different prices for every unit of the product (Shang et al., 2007). This is the only pricing type that, in this review, corresponds to an idea of perfect price discrimination. As such, it is commonly considered as only a theoretical concept.

3. Second-degree price discrimination:

a) Part/tier/block tariff: A price is divided into at least two or more blocks. A twopart tariff is the instance of quantity discount (Armstrong, 2008) when a two-part tariff incurs a fixed charge in return for the right to purchase any quantity at a constant marginal price. A general rule, 'the more you buy, the less you pay per unit' is applied in a large variety of quantity discount offers in telecommunications, copyrighted content, electricity supply, and many other industries. It is discussed in a larger quantity of articles, including already mentioned multi-part pricing defense by Coase (1946).

b) Versioning, feature bundling: Is based on product differentiation in quality. Therefore, some authors outside this review also use the term quality-based price discrimination term (Li \& Dinlersoz, 2012; Roach, 2019). According to Cox (2017), it involves releasing different versions of the same underlying product, thereby encouraging consumers to self-select by their willingness-to-pay. Although at first glance, the product differentiation approach differs from quantity-based price differentiation, the idea of segmentation remains. Segmentation by self-select feature allows what Simshauser and WhishWilson (2017) described as an automated sorting device. Differentiation in quality includes a relatively large variety of features and its availability functions. There are fitting examples for software by Shapiro and Varian (2008) in the form of delay, support availability, format, speed of operation, capability, and one of the most fitting, very recent, and widespread - annoyance.

c) Bundling: Described in a seminal article by Stigler (1963) as block-booking. The pricing method was to achieve a greater return for movie selling if they are sold together. In general, it is based on selling any of two or more distinct goods with the bundle price being less than the individual prices (Stole, 2007). Varian (1989) counts it, in its simplest form of quantity bundle, among clear examples of second-degree price discrimination. Stahl and Siegel (2005) saw bundling as its own special form of price discrimination. Shapiro and Varian (2008) considered it as a special form of versioning. Regardless of classification, it is a very widespread strategy since, e.g., various form of bundling represents over $70 \%$ or sales for telecommunication companies (Kopczewski et al., 2018).

4. Third-degree price discrimination:

a) Dynamic pricing: Price per unit varies with time, stock or value. This pricing primarily tracks changes in the underlying supply and demand imbalance (Phillips, 2005). The imbalance suggests a physical out-of-stock situation, but within this review's scope, it stands for network constraints. Such constraints can be a general capacity (Elmaghraby \& Keskinocak, 2003; Neuteleers et al., 2017), congestion issues (Schuler, 2012), and also yield management problem (Schwind \& Wendt, 2002). A typical example is peak pricing in telecommunication with a higher price per minute during a workday or the electric utility industry with a higher price per kWh during a day. In all cases, there is present third-degree price discrimination based on sorting consumers into at least two groups with different price elasticities.

b) Group, segment pricing: Appears in several reviewed studies (Baumol \& Swanson, 2003; Shang et al., 2007; 
Varian, 1996) as different pricing for each different, separated groups of consumers. This pricing is taken as a synonym for the third-degree price discrimination (Shapiro \& Varian, 2008) where separation of groups is not just related to their identification but mainly to the incapability of sharing or reselling goods.

c) Ramsey pricing: Is derived from a theoretical taxation method introduced by Ramsey (1927). Ramsey pricing uses an inverse elasticity rule where the price should be inversely related to their respective elasticity of demand (Munoz-Alvarez et al., 2018; MunozAlvarez \& Tong, 2018; Neuteleers et al., 2017; Raineri \& Giaconi, 2005; Schuler, 2012; Simshauser \& Whish-Wilson, 2017). The application's outcome is differentiated pricing accordingly different demand elasticities of different consumer groups, i.e., third-degree price discrimination.

There can be found more detailed typologies with more types of pricing including reversed price discrimination (Bang \& Kim, 2013), intertemporal price discrimination (Tóbiás, 2018), windowing, pay-what-you-want pricing (Chao et al., 2015), and such. However, let us consider for this article only those types found in the reviewed articles.

\section{Review Method}

The pre-search phase was performed in the EBSCO Discovery Service. This phase identified the topic-related keywords and their word forms since EBSCO Discovery Service provides a wide range of articles. A search query for the Web of Science and the Scopus was carefully compiled after the pre-search overview as: "(pric* discrimination' OR 'nonlinear pric*' $O R$ 'non-linear pric*' OR 'multipart pric*' OR 'multipart pric*' OR 'differential pric*' OR 'dynamic pric *') AND ('sunk cos*' OR 'fixed $\cos ^{* \prime}$ OR 'marginal $\cos ^{* \prime}$ )".

Frequent wildcard use was necessary due to a combination of exact strings in quotes and different possible word forms such as pric-e, pric-ing, pric-es or cos-t, cos-ts. The query was set with a parameter 'all=()' in the Web of Science and with a parameter 'TITLE-ABSKEY ()' in the Scopus. The search performed in autumn 2020 resulted in 159 Web of Science records and 196 Scopus records. Duplicated records were removed from the list, which resulted in a sample of 230 records. Duplicities were identified by a DOI (132 duplicates) or title match (3 additional duplicates).

The screening phase was consisted of a record title, keywords, and foremost abstract examination. A significant number of records was false-positive. It was caused by the complexity of the query. A significant number of papers were focused only on either pricing only or costs only. Manual screening showed in some cases, appropriate keywords were present, but an aim was not relevant. The next group of articles was excluded during an article body examination phase. The main eligibility criteria were set for the final stage of assessment as:

1. Publishing date after 1996. Such a time span is more than double a usual timespan common for systematic or scope reviews. However, the reason is the rise of digital services, i.e., a lot of information and network goods. The date is set intentionally to 1996 when Yahoo! made its IPO becoming the most successful Nasdaq's IPO indicating the sharp rise of 'dotcom' firms that later fueled a stock bubble.

2. Written in the English language.

3. Explicitly stating the cost structure manifesting high or repeated fixed and sunk cost where marginal one is zero or negligible.

There were 50 articles which met the criteria. Their full text versions were analysed and assessed. The most common problem was that the target cost structure issue was in twelve articles only briefly mentioned. The main goal of the article required giving examples of specific markets to which the problem applied to. Additionally, it required an article to discuss or model the impact on price of goods provided under the specific cost conditions. Another 6 articles had to be excluded because they focused on a production phase, supply chain issues, efficiency gained by merging and so missing the link between the cost issue and price. There were four articles which met the third point in the list above however detailed conditions differed from the article focus such an interdependent multi-product marginal cost production issue. Another four articles were not focused on a retail pricing and the last four articles excluded were not adequately focused on the firm. They described only the demand 


\section{Fig. 1: PRISMA scheme}

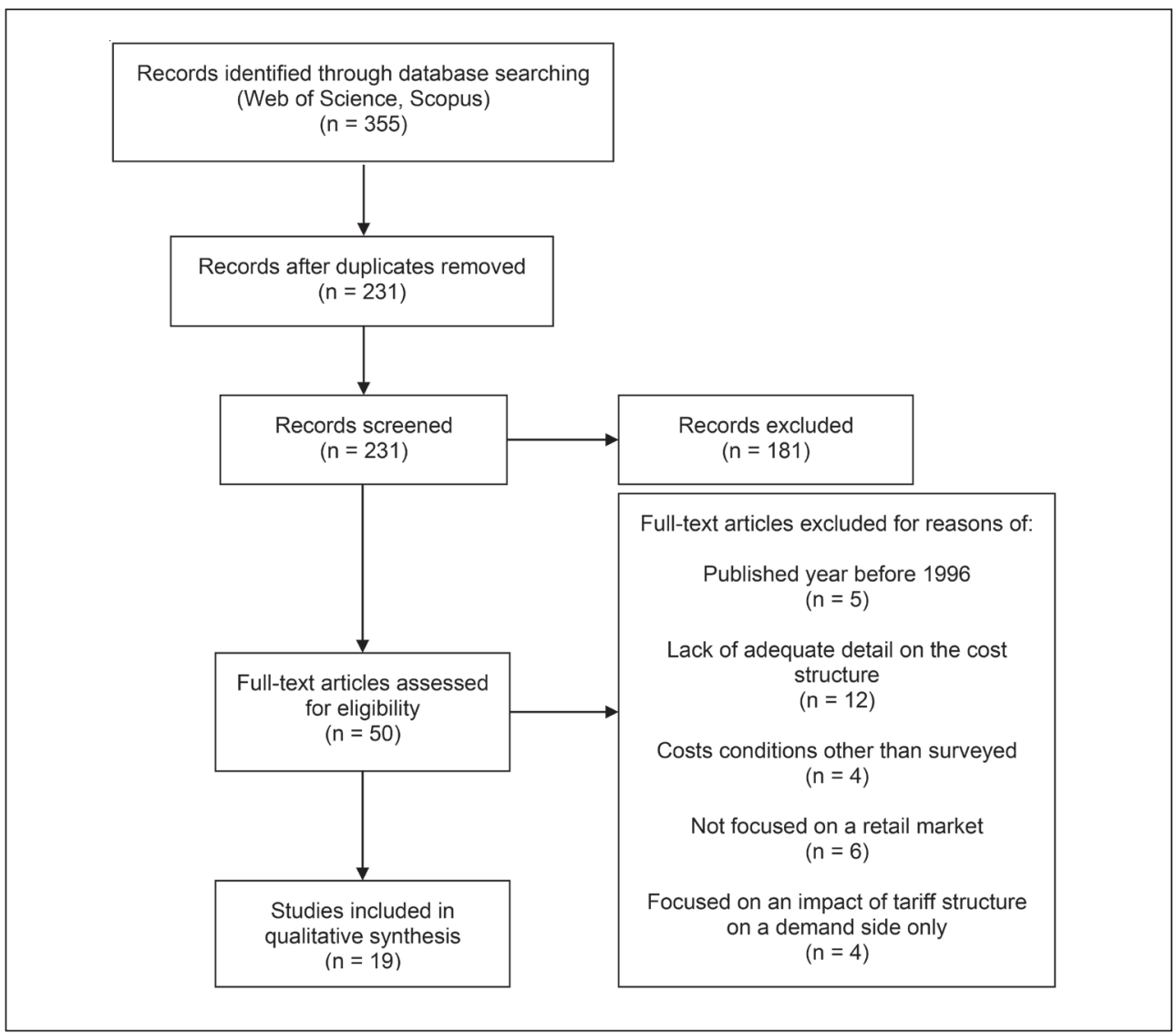

side and only briefly mentioned cost conditions. An overview of the review process can be found in Fig. 1.

\section{Results}

Most of the articles were case studies of a single-product company (Chellappa \& Mehra, 2018; Cox, 2017; Evsukov et al., 2016; MunozAlvarez et al., 2018; Munoz-Alvarez \& Tong, 2018; Nelson et al., 2018; Raineri \& Giaconi, 2005; Simshauser \& Whish-Wilson, 2017) and one multiproduct case (Stahl \& Siegel, 2005). The remaining articles in the sample were theoretical models and discussions focused on:

- cost recovery or profit-maximising models with no specific goods in mind (Abdallah,
2019; Bhargava \& Choudhary, 2001; Huang \& Sundararajan, 2011; Neuteleers et al., 2017; Schuler, 2012; Vickers, 1997);

- a general discussion of the price discrimination problem in connection to the specific cost structure (Baumol \& Swanson, 2003; Varian, 1996);

- an application possibility of other-thanstandard economic methods to solve coststructure-caused issues and their influence on pricing (Schwind \& Wendt, 2002; Shang et al., 2007).

All of the reviewed articles stress the problem of negligible marginal cost. Additionally, there were two more commonly discussed features economies of scale and demand heterogeneity. 
They are described in the 'why' subsection but let us begin with a description of where these issues matter.

\subsection{Network and Information Goods Specific Nature}

This subchapter answers the 'where' part of the main goal. It contributes to the goal by introducing goods and their specific nature leading to price discrimination adoption. All goods, which were mentioned in the reviewed articles, can be divided into two groups: information and network goods. Both groups share the cost structure of high or repeated fixed or sunk cost and zero or negligible marginal cost.

Information goods are characterized by customized retrieval, replication, or generation (Schwind \& Wendt, 2002) and are different from industrial goods (Shang et al., 2007). One of the most distinguishing features is the creation of the first unit, which is extremely costly in comparison to any of the next units. Some authors refer to the problem as an issue of high production but low reproduction cost (Stahl \& Siegel, 2005). Another specific feature is the need for a substrate or an infrastructure in order to be sold. The most comprehensive examples of a substrate are paper, a DVD, memory, or other physical matter containing information goods. An infrastructure example is, e.g., a set of server drives, connection, and account/access management systems. These examples are prerequisites for copyrighted content streaming services, electronic journal subscriptions or paid website content. A substrate or a network represents no value for a consumer. What is crucial and one of the main differences compared to network goods is that a substrate or infrastructure does not play a key part in costs. There is usually no or weak limitation of goods provision.

The second group consists of network goods. Such goods are characterized by an infrastructure needed for their provision. Infrastructure plays a key part in costs, in contrast to information goods. A typical infrastructure example is an electric grid or wireless communication towers that facilitate cellular phones' signal reception. Unlike information goods, network goods are much more a subject of a physical limitation, that is, prone to some form of congestion. It can be solved only by investments expanding the network capacity; otherwise, more consumers cannot be served, or goods' utility cannot be maintained at a current level. There is also a specific feature related to consumer value (Evsukov et al., 2016). The value increase as goods or services become more common. Cell phones provide a user an opportunity to be instantly reached almost anywhere. However, the service value fully manifests only when the user can reach the same way all contacts because they too have a cell phone. Tab. 1 provides a summary of specific goods surveyed, modelled, or discussed in reviewed articles.

\subsection{Network and Information Goods Specific Cost and Market Conditions}

This subchapter answers the 'why' part of the main goal. It contributes to the goal by providing evidence of cost disproportionality found in reviewed articles. It is firstly and foremostly related to high and/or repeated fixed or sunk cost and near or even zero marginal cost. However, secondly, there are factors of economies of scale and demand heterogeneity which also co-create an environment for which a marginal cost set price is not an option.

The main source of fixed/sunk cost comes from an issue provision. However, there is a significant difference in the source of cost. Firstly, there are information goods for which fixed/sunk cost came from creation. In other words, there is high production but low reproduction cost (Stahl \& Siegel, 2005). The most cited example was a software where most of the cost originated in a development (Baumol \& Swanson, 2003; Chellappa \& Mehra, 2018; Cox, 2017; Shang et al., 2007; Varian, 1996). One more installation, one more file downloaded or DVD manufactured, all this created only negligible cost compared to wages of coders, beta-testers, and other human resources needed to deliver safe and efficient software. Movies, series, databases, music clips, journal articles, books, and stock quotes or stock analysis are the same example: one more movie viewer, database user, journal subscriber, ebook downloaded etc, created negligible cost in comparison to good's creation. This problem can be transferred from creator to a reseller. A retailer had to pay royalty payments for a copyrighted content (Abdallah, 2019), licences or other property rights payments (Evsukov et al., 2016) before he could sell any unit. 


\begin{tabular}{|c|c|c|c|c|c|}
\hline & \multicolumn{2}{|c|}{ Article } & \multicolumn{3}{|r|}{ Goods } \\
\hline & 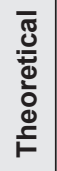 & 范 & 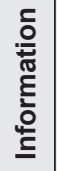 & 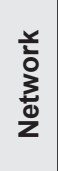 & $\begin{array}{l}\text { Goods that were studied, modelled, } \\
\text { or given as an example of the cost } \\
\text { disproportionality problem }\end{array}$ \\
\hline Abdallah, 2019 & $x$ & & $\mathrm{x}$ & & Streaming of a copyrighted content \\
\hline Baumol \& Swanson, 2003 & $\mathrm{X}$ & & $\mathrm{X}$ & $\mathrm{x}$ & $\begin{array}{l}\text { Magazine publishing, air transportation, } \\
\text { computer software, digital entertainment, } \\
\text { semiconductors, biotechnology, and other } \\
\text { innovative fields }\end{array}$ \\
\hline Bhargava \& Choudhary, 2001 & $\mathrm{X}$ & & $\mathrm{X}$ & & (Digitizable) information goods in general \\
\hline Cox, 2017 & & $\mathrm{X}$ & $x$ & & Video games \\
\hline Evsukov et al., 2016 & & $X$ & & $\mathrm{X}$ & Network goods in general \\
\hline Huang \& Sundararajan, 2011 & $\mathrm{X}$ & & $X$ & & $\begin{array}{l}\text { Digital and IT-enabled 'nondigital' services } \\
\text { (provision of call centre services) }\end{array}$ \\
\hline Chellappa \& Mehra, 2018 & & $\mathrm{x}$ & $\mathrm{X}$ & & Information goods in general \\
\hline Munoz-Alvarez \& Tong, 2018 & & $\mathrm{X}$ & & $x$ & Utilities industry in general \\
\hline Munoz-Alvarez et al., 2018 & & $x$ & & $\mathrm{X}$ & Utilities industry in general \\
\hline Nelson et al., 2018 & & $X$ & & $x$ & Retail electric energy supply \\
\hline Neuteleers et al., 2017 & $\mathrm{X}$ & & & $\mathrm{X}$ & Retail electric energy supply \\
\hline Raineri \& Giaconi, 2005 & & $x$ & & $x$ & Electric energy supply \\
\hline Shang et al., 2007 & $\mathrm{X}$ & & $\mathrm{X}$ & & Information goods in general \\
\hline Schuler, 2012 & $\mathrm{X}$ & & & $\mathrm{X}$ & $\begin{array}{l}\text { Utility projects and any other capital-intensive } \\
\text { facility (infrastructure with substantial } \\
\text { indivisibilities) }\end{array}$ \\
\hline Schwind \& Wendt, 2002 & $\mathrm{X}$ & & & $x$ & $\begin{array}{l}\text { Information product and information services } \\
\text { including automated information production }\end{array}$ \\
\hline Simshauser \& Whish-Wilson, 2017 & & $X$ & & $x$ & Retail electric energy supply \\
\hline Stahl \& Siegel, 2005 & & $\mathrm{X}$ & $x$ & & Paid content digital information goods \\
\hline Varian, 1996 & $x$ & & $x$ & $x$ & $\begin{array}{l}\text { Telecommunications, airlines, publishing, } \\
\text { software, private lighthouse }\end{array}$ \\
\hline Vickers, 1997 & $x$ & & & $x$ & $\begin{array}{l}\text { Utility industry (explicitly mentions gas, } \\
\text { electricity, and telecommunication services) }\end{array}$ \\
\hline
\end{tabular}

Secondly, there are network goods for which fixed/sunk cost rose from an infrastructure needed for their provision. The most typical examples were electricity or telecommunication, for which Schuler (2012) pointed out high costs of construction, which then become sunk. However, such costs were not related to infrastructure construction only.
They were present in the case of capacity expansions as well. It was described by various terms such as capital cost (Munoz-Alvarez et al., 2018; Munoz-Alvarez \& Tong, 2018; Nelson et al., 2018; Schuler, 2012), common capacity (Raineri \& Giaconi, 2005), capacity resourcing, and dynamic standby (Schwind \& Wendt, 2002), and cost associated with maintaining the 
value of the good during service life (Evsukov et al., 2016). One more household connected to the grid, additional phone SIM-card, additional payment account opened, or payment card issued meant negligible cost compared to the cost of infrastructure. Such cost was in the surveyed articles related to electricity or water grid construction, a system for interbank payments/payment gates/ATM network, cellular network terrestrial transmitters, and such capital-intensive endeavours.

Thirdly, there is a common feature which Baumol and Swanson (2003) called an arms race, and Evsukov et al. (2016) described as a high degree of obsolescence. It was shared by almost all information and network goods. The nature of goods and intensifying competition contribute to shortening the lifespan of product generations, series, versions, and models.

Finally, let us finish the fixed/sunk cost issue by maintenance cost. Maintenance is straightforward and related to keeping infrastructure operational. Nevertheless, Evsukov et al. (2016) reminded other sources of cost which rose from sale and after-sale. Such product-maintaining cost includes, for example, call-centers, physical branches with assistants, account management, and other services necessary to maintain value for consumers. Such services are usually offered for free, but they certainly do generate cost. Moreover, it cannot be assigned to a specific unit of production and can only be added ex-ante.

Some reviewed articles have explicitly mentioned additional factors: environment of scale economies or economies of scope (Baumol \& Swanson, 2003; Evsukov et al., 2016; Neuteleers et al., 2017; Raineri \& Giaconi, 2005; Shang et al., 2007; Stahl \& Siegel, 2005; Varian, 1996; Vickers, 1997). The study by Baumol and Swanson (2003) provided the most straightforward problem summarisation that resonated across the reviewed articles: "if average cost decreases as output expands, a marginal cost must be subaverage". Additionally, if the marginal cost is at the near-zero level, the average cost has to be comprised of fixed cost. That is why Baumol and Swanson (2003) claimed that fixed and sunk costs are the source of scale economies. If a company sets a price at the marginal cost, the fixed cost cannot be recovered. A similar opinion had Huang and Sundararajan (2011) and Simshauser and Whish-Wilson (2017).
They noted that in the classic literature, there is no guide on significant sunk or fixed cost recovery, moreover within a short-run debt constraint. Huang and Sundararajan (2011) studied the composition of the average cost discontinuous function and its shape. As a consequence of discontinuous cost, the results demonstrated a stairway-cost pattern and not a smooth continuous function. A high sunk cost had to be paid for each new output interval on which the service can be supplied at almost zero marginal cost. The output capacity growth is extremely discreet.

\subsection{Network and Information Goods Specific Pricing}

This subchapter answers the 'which' part of the main goal. It contributes to the goal by an overview of pricing types found in surveyed articles, see Tab. 2. Not all discussed pricing types were suitable for the specific cost structure the review was focused on.

The next paragraphs provide a summarization for each price discrimination degree. Let us start with the zero-price discrimination, i.e., uniform, flat, or linear tariffs with no price discrimination. They were not found as the optimal solution in either of the articles. Several studies (Huang \& Sundararajan, 2011; Munoz-Alvarez et al., 2018; Neuteleers et al., 2017; Vickers, 1997) discussed them as a benchmark for other pricing methods or as an exogenous feature in the case of regulation. First-degree price discrimination was employed as a benchmark (Abdallah, 2019) as well. The reason was its theoretical nature which might become a real option in the future as more and more data are available about an individual consumer (Baumol \& Swanson, 2003). The real-world examples of second and third-degree price discrimination are between these two extremes of no and perfect price discrimination.

Versioning was successfully employed for cost recovery as well as for profit maximization. However, articles (Bhargava \& Choudhary, 2001; Chellappa \& Mehra, 2018; Cox, 2017) chose different approaches to how to set price and quality. Consumer heterogeneity could be exploited the most in a premium content segment according to Cox (2017), but Chellappa and Mehra (2018) concluded that it was unnecessary to serve the highest willingness-to-pay segment the richest featured version with the highest quality. 


\begin{tabular}{|c|c|c|c|c|c|c|c|c|c|}
\hline $\begin{array}{l}\text { Degree of price } \\
\text { discrimination }\end{array}$ & $\varnothing$ & $1^{\text {st }}$ & & $2^{\text {nd }}$ & & & $3^{\text {rd }}$ & & \\
\hline Article & 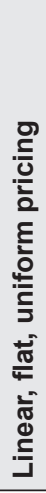 & 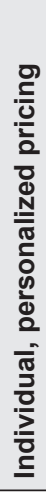 & 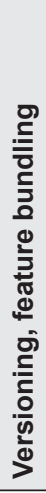 & 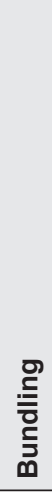 & 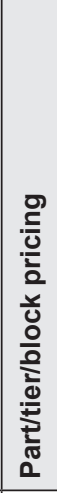 & 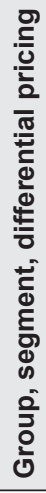 & 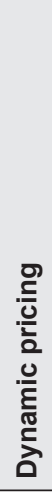 & 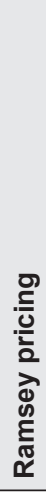 & Market structure \\
\hline Abdallah, 2019 & & $x$ & & $x$ & & & & & Oligopoly \\
\hline Baumol \& Swanson, 2003 & $\mathrm{X}$ & & & & & $\mathrm{X}$ & & & $\begin{array}{l}\text { Oligopoly, monopolistic } \\
\text { competition }\end{array}$ \\
\hline Bhargava \& Choudhary, 2001 & & & $x$ & & & & & & Monopoly \\
\hline Cox, 2017 & & & $\mathrm{X}$ & & & & & & Oligopoly \\
\hline Evsukov et al., 2016 & & & & & & & $x$ & & Monopoly \\
\hline Huang \& Sundararajan, 2011 & $x$ & & & & $x$ & & & & Monopoly \\
\hline Chellappa \& Mehra, 2018 & & & $\mathrm{X}$ & & & & & & Monopoly \\
\hline Munoz-Alvarez \& Tong, 2018 & $x$ & & & & $x$ & & $\mathrm{X}$ & $\mathrm{x}$ & Monopoly (regulated) \\
\hline Munoz-Alvarez et al., 2018 & $x$ & & & & $\mathrm{X}$ & & $\mathrm{X}$ & $\mathrm{x}$ & Monopoly (regulated) \\
\hline Nelson et al., 2018 & & & & & $x$ & & & & Oligopoly \\
\hline Neuteleers et al., 2017 & $x$ & & & & $x$ & & $x$ & $X$ & Monopoly (regulated) \\
\hline Raineri \& Giaconi, 2005 & & & & & & & & $x$ & Monopoly \\
\hline Shang et al., 2007 & & $\mathrm{x}$ & & & & $x$ & & & Monopoly \\
\hline Schuler, 2012 & & & & & & & $\mathrm{X}$ & $\mathrm{X}$ & Not specified \\
\hline Schwind \& Wendt, 2002 & & & & & & & $\mathrm{X}$ & & Not specified \\
\hline Simshauser \& Whish-Wilson, 2017 & & & & & $\mathrm{X}$ & & & & $\begin{array}{l}\text { Oligopoly (regulated, } \\
\text { deregulated) }\end{array}$ \\
\hline Stahl \& Siegel, 2005 & & & & $x$ & $x$ & & & & Oligopoly (presumed) \\
\hline Varian, 1996 & & $x$ & & & $x$ & $\mathrm{x}$ & & & Any \\
\hline Vickers, 1997 & $x$ & & & & $x$ & & & $x$ & $\begin{array}{l}\text { Monopoly (regulated, } \\
\text { unregulated), oligopoly }\end{array}$ \\
\hline
\end{tabular}

The next type was bundling. Two articles investigated a multiproduct company. Abdallah (2019) found that near-zero marginal cost favours pure bundling. The empirical analysis by Stahl and Siegel (2005) considered bundling and non-linear pricing in the form of a multi-part tariff. They concluded that near-zero marginal cost favours larger bundles with larger volumes 
over multi-part tariff providing lower unit price. Nevertheless, both pricing strategies were found suitable.

The largest group of articles employed, modeled, or discussed non-linear pricing for network goods. It was mostly in the form of a twopart tariff, i.e., tariff with a fixed and variable part. Ramsey or Ramsey-like was frequently employed or discussed for the fixed part of a tariff. Simshauser and Whish-Wilson (2017) found such price discrimination cost recovering and also welfare enhancing. Nelson et al. (2018) expanded the (Simshauser \& WhishWilson, 2017) by considering heterogeneous demand. Similarly, they advocate implicit price discrimination. Two related articles about the electricity market (Munoz-Alvarez et al., 2018; Munoz-Alvarez \& Tong, 2018) found as optimal solution two-part tariff: fixed part combined initial-connection and capacity-volume charge, variable part used a dynamic pricing tariff in the form of time-varying markups, i.e., 'Ramsey pricing based on time periods'. An analysis by Neuteleers et al. (2017) compared different approaches for how to set a fair price and allow cost recovery. The two-part tariff option was the best solution and scored the highest in ethical and behavioural economy criteria. A subsequent survey on Dutch consumers also placed this tariff at the front. However, Ramsey and dynamic pricing were found better in allocation efficiency. An article by Huang and Sundararajan (2011) focused on block tariffs. Optimal tariffs should be constructed as multi-part non-linear tariffs with a virtual variable cost that reflects network limitation capacity. Multi-part tariffs were also studied by Stahl and Siegel (2005); see the end of the bundling paragraph. Two theoretical articles (Varian, 1996; Vickers, 1997) discussed non-linear tariffs. Both assessed such pricing in a positive manner. Moreover, Varian (1996) described it as 'a very natural pricing scheme' in the case of a high fixed cost and low marginal environment. In general, non-linear pricing can be more efficient than no price discrimination because low-demand consumers would not be served otherwise.

Group, segment, or differential pricing was discussed in three theoretical articles. Methods employed to set prices were based mostly on dynamic or Ramsey pricing. Such pricing was found by Varian (1996) to be very common. In advocacy of differential pricing, he mentioned cases where a different willingness to pay arises from income limitation rather than from preference. Differential pricing then led to a situation where high-income individuals paid more than low-income consumers. This suggested increased output and total welfare. In the same manner, Baumol and Swanson (2003) mentioned group pricing in comparison to the no-price discrimination scenario. They concluded that no monopoly power must have been present due to a new market entrant threat. The sole fact that price discrimination was present did not mean firms possessed monopoly power. Firms were just limited in a different manner. An article by Shang et al. (2007) proposed the adoption of pricing based on consumer valuation because marginal cost pricing would create a loss for information goods. To achieve it, they proposed the use of CRM tools to classify consumers into groups that can be charged separately.

Dynamic pricing was mostly discussed in articles related to network goods. The typical application was peak and off-peak pricing. Schuler (2012) employs dynamic pricing to solve the problem of sunk cost recovery, and at the same time, it stabilized revenues and smoothed market prices over time. From the demand perspective, some consumers could be encouraged by higher peak prices to shift consumption to off-peak periods. Ramsey pricing is suggested to proportionally distribute the cost burden among different consumers. As mentioned in the multi-part tariff paragraph, Neuteleers et al. (2017) compared several pricing models in terms of fairness. Peak and off-peak pricing were found inferior to two-part tariffs in behavioural economic aspects, despite its allocation effectiveness. An article by Schwind and Wendt (2002) applied an operational research approach to the information goods area. They demonstrated that dynamic pricing and capacity control were successful in fixed costs' coverage by attributing the right capacity type to the right customer type. In contrast to other articles, Evsukov et al. (2016) focused on dynamic pricing as a result of increased valuation by consumers and various sources of fixed costs related to after-sale. Evsukov et al. (2016) recommended pricing accordingly to which cost was higher. Sales revenue focus was optimal in the case of negligible after-sale cost, and by contrast, subscription-oriented revenue was recommended for a significant after-sale cost situation. 
Ramsey pricing was employed both as a possible solution (Munoz-Alvarez et al., 2018; Munoz-Alvarez \& Tong, 2018; Raineri \& Giaconi, 2005; Schuler, 2012; Simshauser \& WhishWilson, 2017) or as a benchmark (Vickers, 1997). Ramsey pricing was applied by MunozAlvarez and Tong (2018) to time periods as time period price markups' settings in two-part tariffs. The consumer and time-based approach led to a successful fixed and sunk cost recovery. However, it performed worse in comparison to two-part tariffs, and there was a problem of the lack of data on short-term price elasticities. In an empirical study, Raineri and Giaconi (2005) found the Ramsey pricing as the most social welfare efficient scenario. However, similarly to (Munoz-Alvarez \& Tong, 2018), the authors acknowledged the information problem. In a fairness assessment study, Neuteleers et al. (2017) saw Ramsey pricing as suitable for cost recovery but also controversial. Ramsey pricing scored the worst in a consumer survey when it was considered unfair by $72 \%$ of consumers in a survey. Schuler (2012) called the Ramsey pricing in outlined dynamic pricing as "most economically efficient way for cost recovery". A more general and theoretical perspective was provided by Vickers (1997), who employed Ramsey pricing as a benchmark to which other pricing methods were compared. The article stressed the pricing problem as a conflict of market efficiency versus cost recovery. In the case when all costs must be recovered by company revenue, Vickers (1997) suggested applying Ramsey pricing in the fixed part a twopart tariff to recover the fixed cost. The reason is to set a variable tariff part close to marginal cost.

At the end of the pricing section, let me present a few alternatives to how to achieve marginal cost pricing and fixed/sunk cost recovery simultaneously. Only a few reviewed articles discussed such alternatives. The first option required subsidies for a company, and so marginal cost prices entail subsidies (Neuteleers et al., 2017; Vickers, 1997). The negative impact was, they would entail a tax increase and would thus have created productive inefficiency somewhere else. A similar negative perspective shared Simshauser and WhishWilson (2017) when citing (Coase, 1946) and his preference of multipart tariff prior to subsidies. The second option is to subsidise consumers with a low ability to pay (Varian,
1996). In this case, goods are not purchased at marginal cost prices. However, a direct social welfare subsidy compensates for the difference between the tariff price and marginal cost set price. Another option with the same result was mentioned by Munoz-Alvarez et al. (2018) as a cross-subsidising. It meant that high-income consumers subsidised low-income consumers who paid a marginal cost price. Real-world examples have been provided by Nelson et al. (2018) and Simshauser and Whish-Wilson (2017) for highly discounted tariffs with prices below industry average cost. Nevertheless, this mechanism requires highly efficient consumer sorting. The last option was available for a multiproduct company. A service could be priced at the marginal cost level. However, fixed costs had to be simultaneously recovered through the remaining services (Raineri \& Giaconi, 2005), in other words, price/cost markups had to differ for each product (Vickers, 1997).

\section{Discussion}

Here, I confront reviewed articles conclusions with selected, mostly behavioural economy, articles discussing a retail market of payment accounts and other financial services (Carlin, 2009; Ellison \& Wolitzky, 2012; Gu \& Wenzel, 2017; Schiff, 2008; Spiegler, 2016), telecommunications (Friesen \& Earl, 2015; Gu \& Wenzel, 2017; Lunn, 2013; Podesta \& Poudou, 2012; Schiff, 2008; Spiegler, 2016), electricity (Chioveanu \& Zhou, 2013; Podesta \& Poudou, 2012), and books (Carlin, 2009). I suggest for each article how to reflect evidence from reviewed articles; see the following paragraphs. Let me remind you that we are still under specific conditions of cost disproportionality, heterogeneous demand, and scale economies. Evidence in reviewed articles leads me to conclude that second and third-degree price discrimination methods are suitable for cost recovery, unlike marginal cost pricing with no price discrimination. No price discrimination can provide cost recovery under a specific setting, such as a flat or linear tariff set above marginal cost, i.e., at the level of total average cost. However, the welfare results are inferior compared with price discrimination (Baumol, 2006; Huang \& Sundararajan, 2011; Neuteleers et al., 2017; Varian, 1996).

Carlin (2009) aimed to demonstrate a possible misuse, from a demand perspective, 
of pricing and gave examples of payment accounts, other financial services, and books. He concluded that "price dispersion persists even when goods are homogeneous and prices do not converge to marginal cost despite a large number of firms". Both Carlin (2009) and also Grubb and Osborne (2015) explained such a situation as a result of market power, i.e., monopoly power. First, I argue, authors should acknowledge that price cannot converge to marginal cost because of special conditions in the markets. Even Carlin (2009) mentioned that firms face zero marginal costs. Yet, he ignored it later in his conclusion and complained about prices 'not converging to marginal cost'. Second, I cannot agree that the source is monopoly power only. Articles (Baumol \& Swanson, 2003; Levine, 2002; Varian, 1989, 1996) gave examples that price discrimination could be present without any monopoly power in the case of information and network goods. Therefore, I suggest assessing entry barriers first and then comment on monopoly power. Carlin (2009) also discussed price complexity which rose from partitioning prices. The problem is that a price with more components includes part tariffs and other examples in Tab. 2 . I strongly suggest acknowledging that such pricing is necessary for cost recovery. Thus, some price partitioning level has to be accepted because of special conditions in the market. Otherwise, some market segments would not be served at all or companies would not be able to recover their cost (Baumol \& Swanson, 2003; Varian, 1996).

Ellison and Wolitzky (2012) mentioned a payment account list of fees as a complex structure, i.e. an example of high price complexity. Let me present an example where this issue is solved, and there is no pricerelated cognitive burden - a payment account with just one fixed monthly fee covering all included services. However, this is explicit price discrimination - bundling. Stahl and Siegel (2005) proved bundling being more efficient in profit maximization than non-linear tariffs. It attracted more consumers, and they described it as 'skimming consumer surplus'. Such trade-off is likely not the result Ellison and Wolitzky (2012) desired, although it solved their fee issue. Therefore, again, some complexity should have been accepted and acknowledged as justified. There is another evidence of such a trade-off effect between complexity and consumer surplus. Homburg (2014) suggested that a company could charge a premium for price simplicity, that is, profit from an intentionally simplified tariff.

Schiff (2008) studied the 'waterbed' effect inside a multiproduct company such as a bank or mobile telephone company. I argue that the 'waterbed' effect is not a marginal cost interdependence phenomenon in these markets. It is a case of products crosssubsidizing, see the principle in the reviewed article (Raineri \& Giaconi, 2005) or the example of printers and ink (van Boom, 2011).

Behavioural studies of telecommunication services focused mostly on the consumer choice being cognitively demanding as a result of tariff construction. Lunn (2013) concluded that part tariff is justified if it is more comfortable from a consumer perspective. I cannot agree. Multi-part pricing should have been described as cost-recovery forced. Its base is justified from the cell carrier side. The term 'confusopoly' was mentioned by Friesen and Earl (2015) in the sense that cell carriers are using multi-part tariffs to create consumer confusion instead of competition. This is in discord with several authors (Baumol \& Swanson, 2003; Levine, 2002; Varian, 1989, 1996). They provided examples suggesting that, e.g., multi-part tariffs exist even in monopolistically competitive markets. Price discrimination was adopted in spite of intensive competition. Friesen and Earl (2015) did not distinguish a necessary multipart tariff structure from on-purpose complexity. Specific conditions in studied markets lead to the unexpected effect. If competition increases, it leads to greater price dispersion (Baumol \& Swanson, 2003; Simshauser \& WhishWilson, 2017). There is another hit to a general economic idea of the fix-all effect of competition. Consumer confusion might not be diminished by a competition increase (Kalaycı \& Potters, 2011), and the same applies to obfuscation (Spiegler, 2016).

$\mathrm{Gu}$ and Wenzel (2017) discussed and modeled obfuscation for both the telecommunication and retail financial markets. There were two options: high marginal cost and low marginal cost firms. Accordingly (Schuler, 2012; Schwind \& Wendt, 2002; Varian, 1996; Vickers, 1997), a marginal cost should be to be close to zero in these markets. Therefore, I suggest excluding high marginal cost option outcomes. Gu and Wenzel (2014) gave 
another obfuscation study an example of an obfuscation technique by increasing price elements in a mobile phone plan, and Spiegler (2016) mentions in a similar manner 'excessive nonlinearity'. Distinct price elements are the base of part/block tariffs, which is optimal for network goods (Huang \& Sundararajan, 2011; Munoz-Alvarez et al., 2018; Munoz-Alvarez \& Tong, 2018; Simshauser \& Whish-Wilson, 2017; Stahl \& Siegel, 2005). Therefore, I suggest accepting a certain level amount of price elements as a base level. This is not limited to just part tariffs. Similarly, when van Boom (2011) discusses the transparency issue of bundling, I suggest acknowledging some cost-justified bundling intransparency under our specific conditions.

The energy and telecommunication markets were modeled by Podesta and Poudou (2012) as environments with a linear cost function. I find it hard to accept because Huang and Sundararajan (2011) demonstrated the discontinuous cost issue for the electricity market. Cost manifested a stairway-cost pattern with no linear parts. Moreover, energy, network, and other components are a widespread base for bill calculation across European countries (see Tab. A1 in Schleich et al., 2019). Again, no linearity. Another study I confront published Chioveanu and Zhou (2013). Their marginal cost was 'normalised to zero'. However, the problem was that firms set the price at marginal cost in several of their model equilibria. Such pricing is in overall discord with (Munoz-Alvarez et al., 2018; Munoz-Alvarez \& Tong, 2018; Nelson et al., 2018; Raineri \& Giaconi, 2005; Simshauser \& Whish-Wilson, 2017; Vickers, 1997).

Conclusions by Neuteleers et al. (2017) are in accordance with behavioural studies of consumer confusion. Behavioural economy causality is as follows: There are incentives to increase consumer's inability to properly assess or to compare distinct products' value because it can decrease demand elasticity (Kalaycı, 2015). The outcome is highly unfair when firms adopt Ramsey pricing. Confused and vulnerable consumers are practically subsiding those who can evaluate goods properly, elastically respond, and pay a lower price. Neuteleers et al. (2017) conclusion was that Ramsey pricing is unfair and controversial. Nevertheless, such a phenomenon is common and well-founded in a behavioural economy where naïve consumer prices create a subsidylike effect on sophisticated demand prices. The survey by Neuteleers et al. (2017) found a peak pricing much less fair than the multipart tariffs. This finding is in accordance with Frey and Pommerehne (1993). They demonstrated that price increases were in the case of excessive demand considered unfair by $80 \%$ of consumers.

\section{Conclusions}

The goal of this review is to provide an overview of why, where, and which type of pricing cannot be plainly condemned as an attempt of firms to obfuscate prices and to exploit consumers. This problem was present in studies concerning information and network goods such as payment accounts and other financial services (Carlin, 2009; Ellison \& Wolitzky, 2012; Gu \& Wenzel, 2017; Schiff, 2008; Spiegler, 2016), telecommunications (Friesen \& Earl, 2015; Gu \& Wenzel, 2017; Lunn, 2013; Podesta \& Poudou, 2012; Schiff, 2008; Spiegler, 2016), electricity (Chioveanu \& Zhou, 2013; Podesta \& Poudou, 2012), and books (Carlin, 2009). Price discrimination was there considered only as means for companies to increase profits, which prevents a market from performing efficiently - marginal cost set price. This is in discordance with the reviewed microeconomic and operational research articles from the last fifteen years. They explained why price discrimination was necessary, and in some cases, even beneficial. I want to stress that no reviewed article disputed that price discrimination increases cognitive demands or challenged existence of the obfuscation phenomenon. Thus, there is no dispute to what was aptly expressed by, e.g., Kalaycl (2015): "Figuring out the price can be a daunting task". He gave an example of a phone call, which is a textbook example of a network good.

The main conclusion is that a certain price complexity level has to be accepted and taken as a starting point. In other words, the mere presence of price discrimination in the case of information and network goods is not a market failure, temporary oddity, sign of monopoly power. The matter is more complicated. Let us follow the goal separation into where, why, and which parts. The answer to 'where' part is the market of information or network goods. The reason 'why' is their specific conditions. The need to adopt price discrimination rises 
from substantial or repeated fixed/sunk cost, economies of scale, and demand heterogeneity environment. One more electricity user, one more cell carrier plan subscriber, one more bank client, or one more cloud storage user all created a negligible marginal cost compared with costs necessary for even a possibility of the service provision - the network. One more streamed movie spectator, one more application downloaded, one more book printed, one more trading account opened, and one more journal screened induces a negligible marginal cost compared with the costs necessary to create information goods. Another sign of this issue the cost function chart which resembles a stairway pattern (Huang \& Sundararajan, 2011) or a jagged pattern (Schuler, 2012).

Which pricing is suitable to cope with the special conditions? Firstly and foremost, reviewed articles brought evidence that marginal pricing is not suitable for such an environment. Our specific conditions should not be seen through the general economy lens. Second, no or perfect price discrimination can be used as benchmarks. Finally, both the second and third-degree price discrimination pricing methods were suitable pricing methods. They allowed cost recovery, but they also resulted in greater welfare in comparison to no price discrimination. Part tariffs were a typical example of second-degree price discrimination. It was even described as a 'very natural pricing scheme' (Varian, 1996) and scored the highest in ethical and behavioural economy criteria (Neuteleers et al., 2017). The fixed tariff part recovered (most) of fixed cost, and thus variable tariff part could be set closer to marginal costs (Varian, 1996; Vickers, 1997) in order to minimize a dead-weight loss. Typical thirddegree price discrimination employed dynamic and Ramsey pricing. A typical form is a peak and off-peak pricing. Such pricing recovered fixed/sunk costs and smoothed market prices over time (Schuler, 2012).

The review has several limitations. There are other articles discussing or information and network goods or other relevant topics such as the marginal cost controversy. They were not included in the review because the timespan was from 1996, and I insisted on an explicit statement of high or repeated fixed/sunk cost and near-zero marginal cost. How a consumer deals with a pricing was topical in the last fifteen years, mainly thanks to the behavioural economy. Thus, many articles modelled, experimented and discussed price obfuscation, complexity, intransparency. I neither screened nor inspected all those articles because the goal of the review is different. I included only several articles to demonstrate the problem I seek to fix. I see the main challenge for further research of the matter in the base price complexity level. In other words, to clearly separate the justified price complexity from the one created on purpose. Some reviewed articles already provided clues. That is what I believe to be the 'true' on purpose obfuscation.

Acknowledgment: The article was supported by the specific research and Excellency grant at the Faculty of Informatics and Management of the University of Hradec Králové grant, Czech Republic.

\section{References}

Abdallah, T. (2019). On the Benefit (Or Cost) of Large-Scale Bundling. Production and Operations Management, 28(4), 955-969. https://doi.org/10.1111/poms.12958

Armstrong, M. (2008). Price Discrimination. In P. Buccirossi (Ed.), Handbook of Antitrust Economics (pp. 433-467). Cambridge, MA: MIT Press.

Bang, S. H., \& Kim, J. (2013). Price discrimination via information provision. Information Economics and Policy, 25(4), 215-224. https://doi.org/10.1016/j.infoecopol.2013.06.001

Baumol, W. J. (2006). Regulation Misled by Misread Theory: Perfect Competition and Competition-Imposed Price Discrimination. Washington, DC: AEI-Brookings Joint Center for Regulatory Studies.

Baumol, W. J., \& Swanson, D. G. (2003). The new economy and ubiquitous competitive price discrimination: Identifying defensible criteria of market power. Antitrust Law Journal, 70(3), 661-685.

Bhargava, H. K., \& Choudhary, V. (2001). Second-degree price discrimination for information goods under nonlinear utility functions. In Proceedings of the 34th Annual Hawaii International Conference on System Sciences (p. 6). Maui, HI, USA. https://doi. org/10.1109/HICSS.2001.927070

Carlin, B. I. (2009). Strategic price complexity in retail financial markets. Journal of Financial Economics, 91(3), 278-287. https://doi.org/10.1016/j.jfineco.2008.05.002 
Chao, Y., Fernandez, J., \& Nahata, B. (2015). Pay-what-you-want pricing: Can it be profitable? Journal of Behavioral and Experimental Economics, 57, 176-185. https://doi.org/10.1016/j.socec.2014.09.004

Chellappa, R. K., \& Mehra, A. (2018). Cost Drivers of Versioning: Pricing and Product Line Strategies for Information Goods. Management Science, 64(5), 2164-2180. https://doi. org/10.1287/mnsc.2016.2698

Chioveanu, I., \& Zhou, J. (2013). Price Competition with Consumer Confusion. Management Science, 59(11), 2450-2469. https://doi.org/10.1287/mnsc.2013.1716

Coase, R. H. (1946). The Marginal Cost Controversy. Economica, 13(51), 169. https://doi.org/10.2307/2549764

Cox, J. (2017). Play It Again, Sam? Versioning in the Market for Second-hand Video Game Software. Managerial and Decision Economics, 38(4), 526-533. https://doi.org/10.1002/mde.2800

Duffy, J. F. (2004). The Marginal Cost Controversy in Intellectual Property. University of Chicago Law Review, 71(1), 37-56. Retrieved from https://chicagounbound.uchicago.edu/ uclrev/vol71/iss $1 / 4$

Ellison, G., \& Wolitzky, A. (2012). A search cost model of obfuscation. The RAND Journal of Economics, 43(3), 417-441. https://doi. org/10.1111/j.1756-2171.2012.00180.x

Elmaghraby, W., \& Keskinocak, P. (2003). Dynamic Pricing in the Presence of Inventory Considerations: Research Overview, Current Practices, and Future Directions. Management Science, 49(10), 1287-1309. https://doi. org/10.1287/mnsc.49.10.1287.17315

Evsukov, S. G., Sigarev, A. V., Ustyuzhanina, E. V., \& Zaytseva, E. V. (2016). Comparative analysis of pricing policies in the market for network goods. Journal of Internet Banking and Commerce, 21(S6).

Frey, B. S., \& Pommerehne, W. W. (1993). On the fairness of pricing - An empirical survey among the general population. Journal of Economic Behavior \& Organization, 20(3), 295-307. https://doi.org/10.1016/01672681(93)90027-M

Friesen, L., \& Earl, P. E. (2015). Multipart tariffs and bounded rationality: An experimental analysis of mobile phone plan choices. Journal of Economic Behavior \& Organization, 116, 239253. https://doi.org/10.1016/j.jebo.2015.04.016

Grubb, M. D. (2015). Failing to Choose the Best Price: Theory, Evidence, and Policy.
Review of Industrial Organization, 47(3), 303-340. https://doi.org/10.1007/s11151-0159476-x

Grubb, M. D., \& Osborne, M. (2015). Cellular Service Demand: Biased Beliefs, Learning, and Bill Shock. American Economic Review, 105(1), 234-271. https://doi.org/10.1257/aer.20120283

Gu, Y., \& Wenzel, T. (2014). Strategic Obfuscation and Consumer Protection Policy: Strategic Obfuscation and Consumer Protection Policy. The Journal of Industrial Economics, 62(4), 632-660. https://doi.org/10.1111/joie.12060

Gu, Y., \& Wenzel, T. (2017). Consumer confusion, obfuscation and price regulation. Scottish Journal of Political Economy, 64(2), 169-190. https://doi.org/10.1111/sjpe.12121

Homburg, C., Totzek, D., \& Krämer, M. (2014). How price complexity takes its toll: The neglected role of a simplicity bias and fairness in price evaluations. Journal of Business Research, 67(6), 1114-1122. https://doi. org/10.1016/j.jbusres.2013.05.049

Hotelling, H. (1938). The General Welfare in Relation to Problems of Taxation and of Railway and Utility Rates. Econometrica, 6(3), 242-269. https://doi.org/10.1007/978-1-4613-8905-7_10

Huang, K.-W., \& Sundararajan, A. (2011). Pricing Digital Goods: Discontinuous Costs and Shared Infrastructure. Information Systems Research, 22(4), 721-738. https://doi. org/10.1287/isre.1100.0283

Kalaycı, K. (2015). Price complexity and buyer confusion in markets. Journal of Economic Behavior \& Organization, 111, 154168. https://doi.org/10.1016/j.jebo.2015.01.001

Kalaycı, K., \& Potters, J. (2011). Buyer confusion and market prices. International Journal of Industrial Organization, 29(1), 14-22. https://doi.org/10.1016/j.ijindorg.2010.06.004

Kalaycı, K., \& Serra-Garcia, M. (2016). Complexity and biases. Experimental Economics, 19(1), 31-50. https://doi.org/10.1007/s10683015-9434-3

Kopczewski, T., Sobolewski, M., \& Miernik, I. (2018). Bundling or unbundling? Integrated simulation model of optimal pricing strategies. International Journal of Production Economics, 204, 328-345. https://doi.org/10.1016/j.jppe.2018.08.017

Levine, M. E. (2002). Price Discrimination Without Market Power. Yale Journal on Regulation, 19(1), 2-35.

Li, H., \& Dinlersoz, E. (2012). Qualitybased Price Discrimination: Evidence from Internet Retailers' Shipping Options. Journal 
of Retailing, 88(2), 276-290. https://doi. org/10.1016/j.jretai.2011.12.002

Liberati, A., Altman, D. G., Tetzlaff, J., Mulrow, C., Gøtzsche, P. C., loannidis, J. P. A., Clarke, M., Devereaux, P. J., Kleijnen, J., \& Moher, D. (2009). The PRISMA Statement for Reporting Systematic Reviews and MetaAnalyses of Studies That Evaluate Health Care Interventions: Explanation and Elaboration. PLoS Medicine, 6(7), e1000100. https://doi. org/10.1371/journal.pmed.1000100

Lunn, P. D. (2013). Telecommunications Consumers: A Behavioral Economic Analysis: Telecommunications Consumers. Journal of Consumer Affairs, 47(1), 167-189. https://doi. org/10.1111/j.1745-6606.2012.01245.x

Munoz-Alvarez, D., Garcia-Franco, J. F., \& Tong, L. (2018). On the Efficiency of Connection Charges - Part II: Integration of Distributed Energy Resources. IEEE Transactions on Power Systems, 33(4), 3834-3844. https://doi. org/10.1109/TPWRS.2017.2782791

Munoz-Alvarez, D., \& Tong, L. (2018). On the Efficiency of Connection Charges - Part I: A Stochastic Framework. IEEE Transactions on Power Systems, 33(4), 3822-3833. https://doi. org/10.1109/TPWRS.2017.2782802

Nelson, T., McCracken-Hewson, E., WhishWilson, P., \& Bashir, S. (2018). Price dispersion in Australian retail electricity markets. Energy Economics, 70, 158-169. https://doi. org/10.1016/j.eneco.2017.12.026

Neuteleers, S., Mulder, M., \& Hindriks, F. (2017). Assessing fairness of dynamic grid tariffs. Energy Policy, 108, 111-120. https://doi. org/10.1016/j.enpol.2017.05.028

Phillips, R. L. (2005). Pricing and Revenue Optimization. Redwood City, CA: Stanford Business Books.

Podesta, M., \& Poudou, J.-C. (2012). Bundling Commodities and Attached Services with Nonlinear Pricing. Recherches économiques de Louvain, 78(2), 25-52. https:// doi.org/10.3917/rel.782.0025

Raineri, R., \& Giaconi, P. (2005). Price and access charge discrimination in electricity distribution: An application to the Chilean case. Energy Economics, 27(5), 771-790. https://doi. org/10.1016/j.eneco.2005.04.001

Ramsey, F. P. (1927). A Contribution to the Theory of Taxation. The Economic Journal, 37(145), 47-61. https://doi.org/10.2307/2222721

Roach, T. (2019). Market power and second degree price discrimination in retail gasoline markets. Energy Economics, 84, 104514. https://doi.org/10.1016/j.eneco.2019.104514

Robinson, J. (1933). The Economics of Imperfect Competition. London: Palgrave Macmillan UK. https://doi.org/10.1007/978-1349-15320-6

Schiff, A. (2008). The "Waterbed" Effect and Price Regulation. Review of Network Economics, 7(3), 392-414. https://doi. org/10.2202/1446-9022.1155

Schleich, J., Faure, C., \& Gassmann, X. (2019). Household internal and external electricity contract switching in EU countries. Applied Economics, 51(1), 103-116. https://doi. org/10.1080/00036846.2018.1494379

Schuler, R. E. (2012). Pricing the use of capital-intensive infrastructure over time and efficient capacity expansion: Illustrations for electric transmission investment. Journal of Regulatory Economics, 41(1), 80-99. https:// doi.org/10.1007/s11149-011-9176-x

Schwind, M., \& Wendt, O. (2002). Dynamic Pricing of Information Products Based on Reinforcement Learning: A Yield-Management Approach. In M. Jarke, G. Lakemeyer, \& J. Koehler (Eds.), KI 2002: Advances in Artificial Intelligence (Vol. 2479, pp. 51-66). Berlin, Heidelberg: Springer. https://doi.org/10.1007/3540-45751-8_4

Shang, W., Wu, H., \& Ji, Z. (2007). Applying CRM in information product pricing. In $\mathrm{S}$. Chaudhry, L. Xu, \& A. Tjoa (Eds.), Research and Practical Issues of Enterprise Information Systems II (Vol. 255, pp. 1407-1411). Berlin, Heidelberg: Springer.

Shapiro, C., \& Varian, H. R. (2008). Information Rules: A Strategic Guide to the Network Economy. Brighton, MA: Harvard Business School Press.

Simshauser, P., \& Whish-Wilson, P. (2017). Price discrimination in Australia's retail electricity markets: An analysis of Victoria \& Southeast Queensland. Energy Economics, 62, 92-103. https://doi.org/10.1016/j.eneco.2016.12.016

Spiegler, R. (2016). Choice Complexity and Market Competition. Annual Review of Economics, 8(1), 1-25. https://doi.org/10.1146/ annurev-economics-070615-115216

Stahl, F., \& Siegel, F. (2005). Nonlinear Pricing of Paid Content Products. In Proceedings of the 18th Bled EConference Elntegration in Action. Bled, Slovenia.

Stigler, G. J. (1963). United States v. Loew's Inc.: A Note on Block-Booking. The Supreme 
Court Review, 1963, 152-157. https://doi. org/10.1086/scr.1963.3108731

Stigler, G. J. (1987). The Theory of Price (4th ed). New York, NY: Collier Macmillan.

Stole, L. A. (2007). Price Discrimination and Competition. In M. Armstrong, \& R. Porter (Eds.), Handbook of Industrial Organization (1st ed., Vol. 3, pp. 2221-2299). Amsterdam: Elsevier.

Tóbiás, Á. (2018). Non-linear pricing and optimal shipping policies. Games and Economic Behavior, 112, 194-218. https://doi. org/10.1016/j.geb.2018.08.008

van Boom, W. H. (2011). Price Intransparency, Consumer Decision Making and European Consumer Law. Journal of Consumer Policy, 34(3), 359-376. https://doi. org/10.1007/s10603-011-9163-8

Varian, H. R. (1989). Price Discrimination. In Handbook of Industrial Organization (Vol. 1). Amsterdam: North Holland.

Varian, H. R. (1996). Differential Pricing and Efficiency. First Monday, 1(2), 1-13. https://doi. org/10.5210/fm.v1i2.473

Vickers, J. (1997). Regulation, competition, and the structure of prices. Oxford Review of Economic Policy, 13(1), 15-26. https://doi. org/10.1093/oxrep/13.1.15 